\title{
Influence of Phosphorus on Deformation Mechanism and Mechanical Properties of IN718 Alloy
}

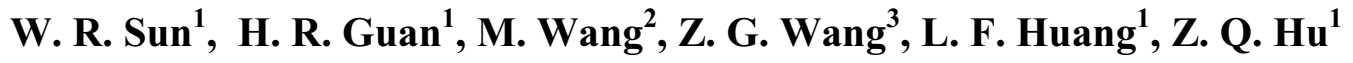 \\ 1. Institute of Metal Research, Chinese Academy of Sciences, Shenyang, 110016, China \\ 2. Shenyang Engine Design and Research Institute, Shenyang, 110015, China \\ 3. Dongbei Special Steel Com. Ltd., Fushun, 113001, China
}

Keywords: Phosphorus, IN718 alloy, Deformation, Mechanical Properties

\begin{abstract}
Phosphorus greatly increased the rupture life, remarkably decreased the creep rate, and reduced the impact energy of the IN718 alloy with an as-heat treated microstructure. However, it did not influence the tensile properties either at room temperature and $650^{\circ} \mathrm{C}$. Phosphorus increased the yield strength of the IN718 alloy with a microstructure free from $\gamma^{\prime \prime}$ phase, and it decreased the creep rate by strengthening the $\gamma$ matrix. Dislocation mechanism operated at the deformation of rolling, and impact and tension test. Twinning mechanism operated at the creep of the IN718 alloy. Creep twinning was a thermal activated process.
\end{abstract}

\section{Introduction}

The IN718 alloy is mainly strengthened by a coherent body centered tetragonal precipitate, $\gamma^{\prime \prime}-\mathrm{Ni}_{3}(\mathrm{Nb}, \mathrm{Al}, \mathrm{Ti})$, and it also contains a FCC $\gamma$ phase, carbides, and orthorhombic $\delta-\mathrm{Ni}_{3} \mathrm{Nb}$ phase. This unique microstructure gives the alloy a good combination of high strength at moderate temperature, corrosion and oxidation resistance, and good creep and fatigue resistance. IN718 is now the most widely used superalloy especially for the manufacture of the critical components such as turbine discs and blades. However, it is well known that alloy 718 is unstable at elevated temperatures, especially after long term exposure at $650^{\circ} \mathrm{C}$ or above, and the improvement of the temperature capability and other properties is of great significance.

It has been found that phosphorus greatly improved the stress rupture and creep properties of some superalloys including the IN718 alloy[1-4]. And recently it was found that the co-addition of phosphorus and boron had a larger effect to prolong the rupture life and lower the steady state creep rate of IN718 alloy[5-6]. We also found recently that the co-addition of phosphorus and boron improved the temperature capability of the IN718 alloy[7]. The mechanisms by which phosphorus influences the stress rupture and creep properties has been investigated extensively, and the works related are mainly focused on the influence of phosphorus on the grain boundaries because the samples always ruptured during creep by an intergranular fracture and phosphorus had a large tendency to be highly concentrated at the grain boundaries[1-7]. However, it is well known that the cracks can initiate and propagate at the grain boundaries when the deformation between the neighbor grains is not harmonized properly. So the concentration of phosphorus at the grain boundaries might not be the only way for it to extend the interganular fracture process. If phosphorus can strengthen the grains, it can also prolong the rupture life. Another reason for the influence of phosphorus on the grains or the matrix to be neglected is that its optimal addition in the alloy is as low as about $0.02 \mathrm{wt} \%$, and it seems 
impossible for phosphorus being dissolved in the capacious $\gamma$ matrix to have so great an effect of extending the rupture life of the alloy over three times[1-4]. But actually phosphorus might not be distributed in the $\gamma$ matrix homogeneously, it is generally concentrated at the defects such as dislocations and interfaces, and hence can influence the mechanical properties by influencing the deformation behavior of the grains or the $\gamma$ matrix. So the evaluation of the effect of phosphorus on the $\gamma$ matrix is necessary for revealing its mechanism influencing the mechanical properties of the alloy.

It was found recently that the IN718 alloy crept by twinning[8]. It can not be sure by now if the twinning is the only deformation mode for the creep of the IN718 alloy, but no dislocations were observed in the post creep materials, and this implies that the twinning is at least a very important deformation mechanism for the creep of the IN718 alloy. In this paper, the creep twinning is investigated and discussed on the base of our previous study[8], and the influence of phosphorus in the $\gamma$ matrix is also studied.

\section{Materials and experimental}

The materials were prepared in a vacuum induction furnace using high-purity raw materials. To minimize the compositional variations among the heats, a master alloy was prepared and its composition was as followings (in wt.\%): Ni 52.70, $\mathrm{Cr}$ 18.91, Mo 3.02, Nb, 5.36, Al 0.55, Ti 0.97, C 0.033, B 0.0043, Fe balance, S 0.0048, $\mathrm{Mn}<0.03, \mathrm{Si}<0.05, \mathrm{~Pb} 0.0005$, Sb 0.001, Sn 0.001, Bi 0.0001, As 0.001. The ingot of the master alloy was split and remelted into four $10 \mathrm{~kg}$ ingots of $20 \mathrm{~cm}$ diameter by $40 \mathrm{~cm}$ height. Phosphorus was doped to designed levels and its composition was chemically analyzed to be (in wt.\%): 0.0008, 0.010, 0.016, 0.040. The ingots underwent a homogenization treatment: $\left(1160^{\circ} \mathrm{C} \times 20 \mathrm{~h}\right)+\left(1240^{\circ} \mathrm{C} \times 12 \mathrm{~h}\right)$. Then they were forged into bars of $45 \mathrm{~mm}$ square section within the temperature range of $1110^{\circ} \mathrm{C}-900^{\circ} \mathrm{C}$, and rolled into round bars of $18 \mathrm{~mm}$ diameter within the temperature range of $1110^{\circ} \mathrm{C}-950^{\circ} \mathrm{C}$. The heat treatment of the as-rolled materials consisted of a solution at $965^{\circ} \mathrm{C} / 1 \mathrm{~h}$ followed by air cooling, and aging at $720^{\circ} \mathrm{C} / 8 \mathrm{~h}$., furnace cooled to $620^{\circ} \mathrm{C}$ in $2 \mathrm{~h}$., aging at $620^{\circ} \mathrm{C} / 8 \mathrm{hs}$, followed by air cooling. The effect of phosphorus on the mechanical properties of the IN718 alloy was evaluated by measuring the creep property at $650^{\circ} \mathrm{C} / 690 \mathrm{MPa}$, tensile properties at room temperature and $650^{\circ} \mathrm{C}$, and Charpy impact property at room temperature. The post test metallographic and fractographic characterization was conducted on the selected test specimens. In addition, the microstructure of the as-rolled materials was also characterized to compare the deformation behavior under various conditions. The as-heat treated materials were subjected to a solution at $1120^{\circ} \mathrm{C} / 1 \mathrm{~h}$, following a water quenching to dissolve the $\gamma^{\prime \prime}$ phase. And then the materials free from $\gamma^{\prime \prime}$ phase were subjected to a tension test at $650^{\circ} \mathrm{C}$ and a creep at $550^{\circ} \mathrm{C}$ /200MPa to evaluate the influence of phosphorus on the $\gamma$ matrix.

\section{Results}

\section{A. On mechanical properties}

The tensile properties of the alloys with the as-heat treated microstructure are shown in Table 1. Consistent with the previous studies, the addition of phosphorus did not noticeably influence the tensile properties of the IN718 alloy either at room and elevated temperature.

The Effect of phosphorus on the Charpy V-notch impact energy of the IN 718 alloy with the as-heat treated microstructure is shown in Fig.1. Phosphorus slightly decreased the impact 
energy when its content is lower than $0.016 \%$, but the impact energy was noticeably lowered when the phosphorus content reached the level of $0.040 \%$.

The result in Fig. 2 which shown the effect of phosphorus on the creep properties of the IN718 alloy with the as-heat treated microstructure has been published in [8], ant it is cited herein for the convenience of discussion because some further works have been done. The primary creep stage of the alloys was not distinct. Phosphorus greatly extended the secondary and tertiary creep stages and remarkably decreased the creep rate of the two stages. As a result, the rupture life was prolonged significantly. When the phosphorus content reached the level of $0.040 \%$, the secondary and tertiary stages reduced markedly, but still longer than that of the alloy with $0.0008 \%$ phosphorus.

Table 1. Effect of phosphorus on the tensile properties at room temperature and $650^{\circ} \mathrm{C}$

\begin{tabular}{|c|c|c|c|c|c|}
\hline $\begin{array}{c}\text { P Content } \\
\%\end{array}$ & $\begin{array}{c}\text { Test } \\
\text { Temperature }\end{array}$ & $\begin{array}{c}\text { YS } \\
\mathrm{MPa}\end{array}$ & $\begin{array}{c}\text { UTS } \\
\mathrm{MPa}\end{array}$ & $\begin{array}{c}\text { EL } \\
\%\end{array}$ & $\begin{array}{c}\text { RA } \\
\%\end{array}$ \\
\hline \hline \multirow{3}{*}{0.0008} & $20^{\circ} \mathrm{C}$ & 1171 & 1400 & 21 & 44 \\
\cline { 2 - 7 } & $650^{\circ} \mathrm{C}$ & 966 & 1168 & 22 & 37 \\
\hline \multirow{2}{*}{0.016} & $20^{\circ} \mathrm{C}$ & 1192 & 1405 & 22 & 43 \\
\cline { 2 - 7 } & $650^{\circ} \mathrm{C}$ & 969 & 1161 & 25 & 50 \\
\hline 0.040 & $20^{\circ} \mathrm{C}$ & 1223 & 1456 & 20 & 36 \\
\cline { 2 - 7 } & $650^{\circ} \mathrm{C}$ & 973 & 1176 & 22 & 46 \\
\hline
\end{tabular}

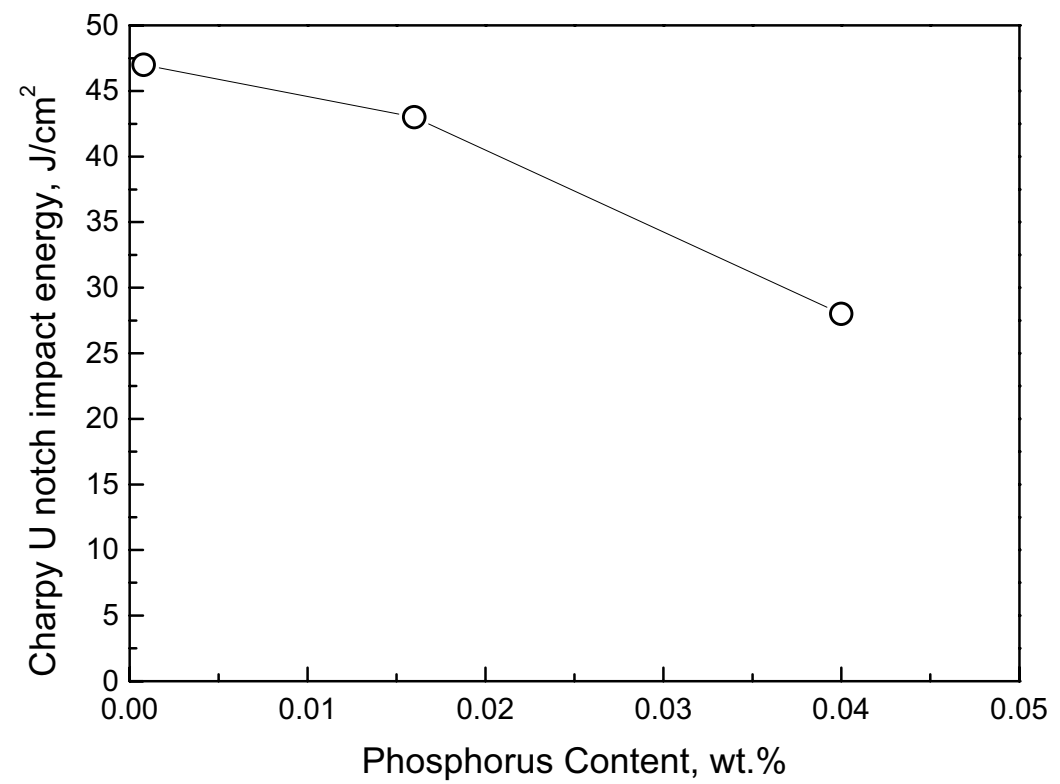

Fig.1 Effect of phosphorus on the Charpy impact energy of the IN718 alloy

The effect of phosphorus on the tensile properties at $650^{\circ} \mathrm{C}$ of the alloys with a microstructure free from $\gamma^{\prime \prime}$ phase is shown in Table 2. It is surprising that phosphorus increased the yield strength of the IN718 alloy under this condition. When the phosphorus content was increased from $0.0008 \%$ to $0.016 \%$, the yield strength was increased slightly. But when the phosphorus content was increased to the level of $0.040 \%$, the yield strength was increased more than $100 \mathrm{MPa}$. And this remarkable increment in strength can surely confirm the phenomenon 
that phosphorus increased the yield strength of the $\gamma$ matrix of the superalloys although its effect at lower content was relatively smaller. A similar test has been performed on a $\gamma^{\prime}$-strengthened alloy, and a similar result has been gained.

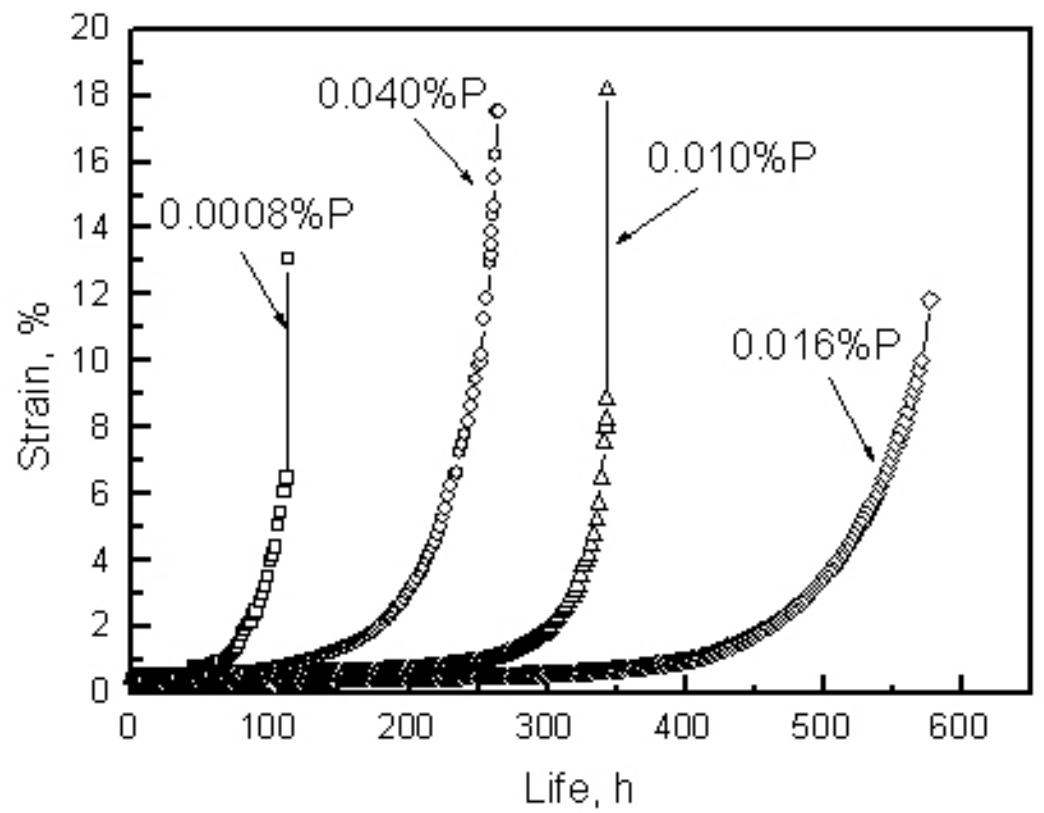

Fig.2 Effect of phosphorus on the creep property of the IN718 alloy at $650^{\circ} \mathrm{C} / 690 \mathrm{MPa}$

Table 2. Effect of phosphorus on the yield strength of the IN718 alloy with a microstructure free from $\gamma^{\prime \prime}$ phase

\begin{tabular}{|c|c|c|c|}
\hline \hline P Content, $\%$ & 0.0008 & 0.016 & 0.040 \\
\hline \hline YS, $\mathrm{MPa}$ & 221 & 234 & 341 \\
\hline
\end{tabular}

\section{B. On Microstructure and Deformation Mechanism}

The as-heat treated microstructure was observed carefully. As shown in Fig.3, the grain size was around $20 \mu \mathrm{m}, \delta$-phase was precipitated at the grain boundaries and small carbides were sometimes observed both at the grain boundaries or inside the grains. As shown in Fig.4, $\gamma^{\prime \prime}$ particles are distributed homogeneously in the $\gamma$ matrix. No evident difference between the microstructures of the alloys with the various phosphorus additions was observed. 


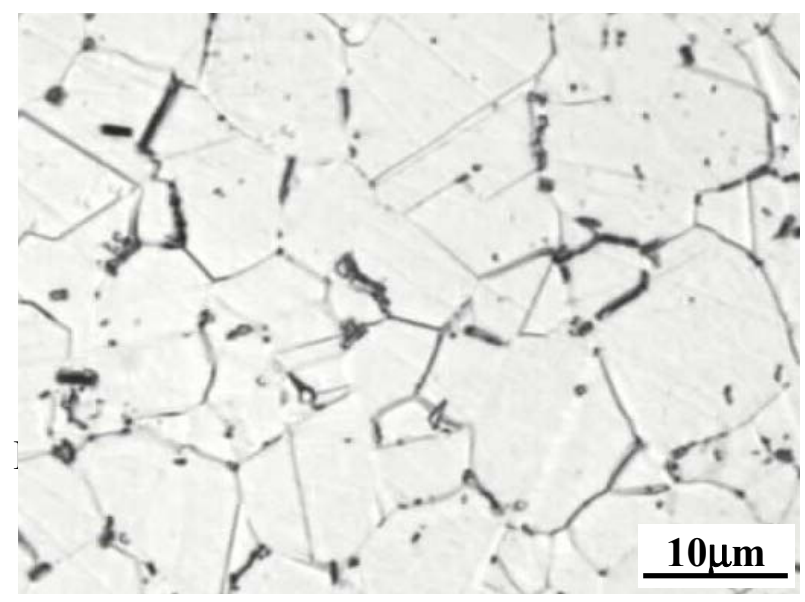

Fig.3 As-heat treated microstructure of IN718 alloy with $0.0008 \%$ phosphorus

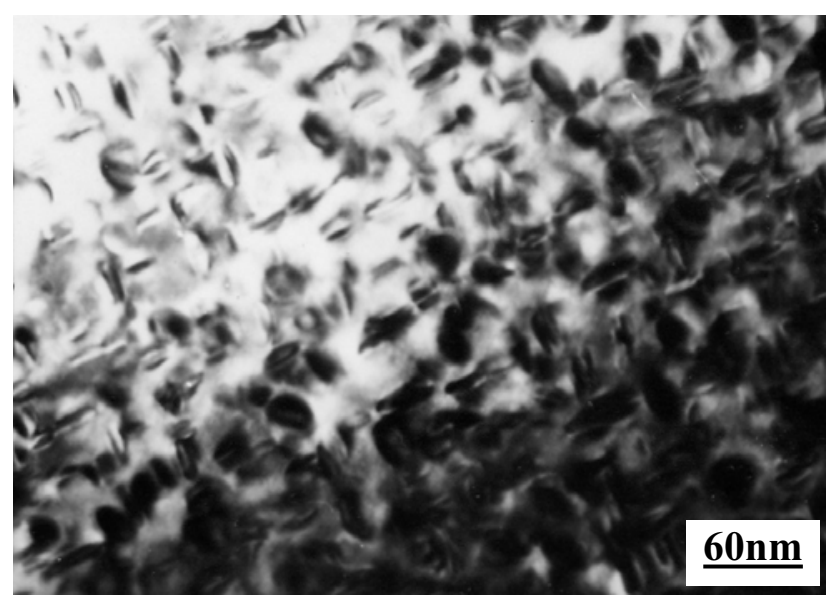

Fig.4 Precipitation of $\gamma^{\prime \prime}$ phase in IN718 alloy with $0.0008 \%$ phosphorus 

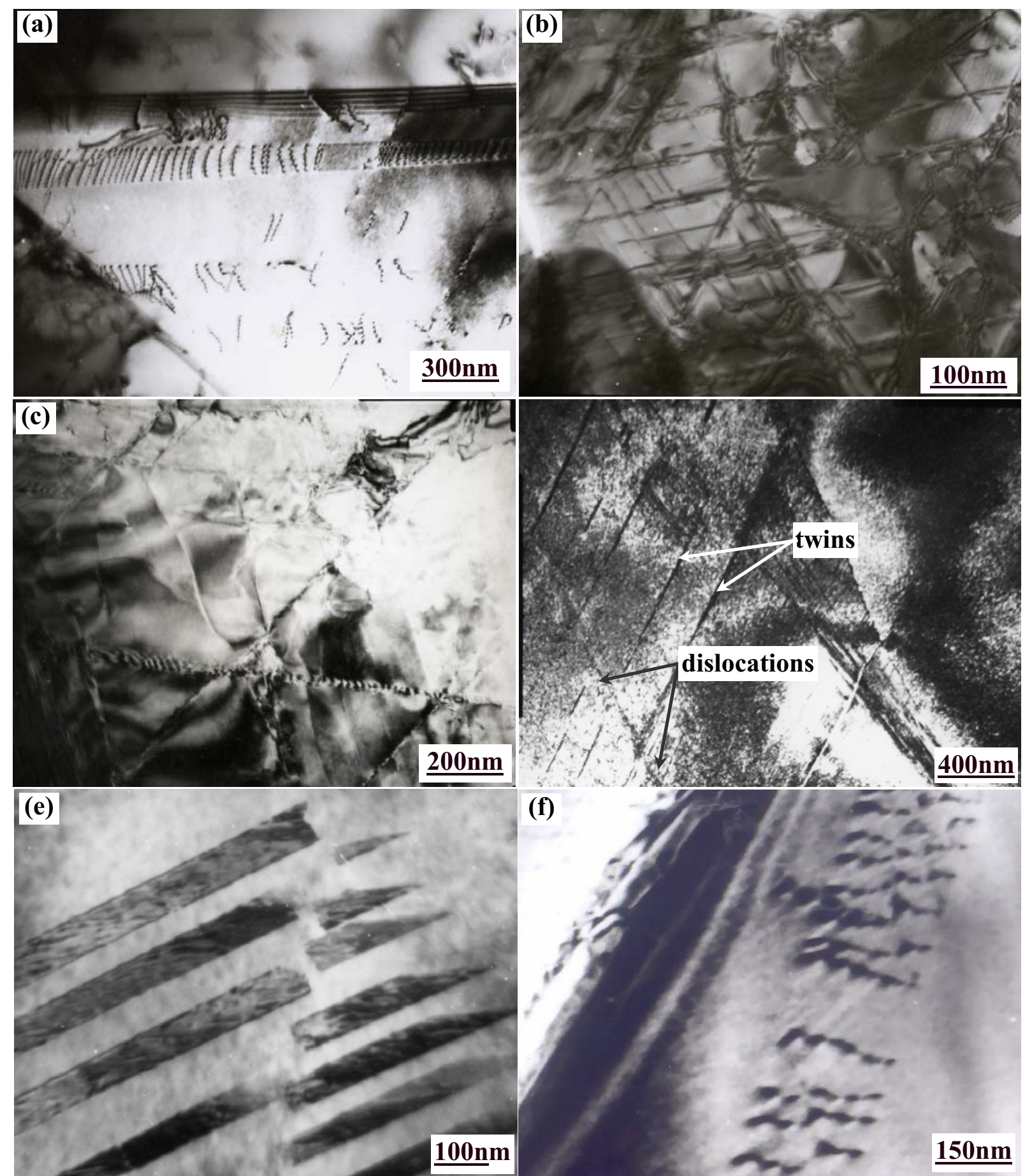

Fig.5 Microstructure of IN718 alloy deformed under various conditions. (a) rolled at $1110^{\circ} \mathrm{C}-950^{\circ} \mathrm{C}$; (b) as-heat treated, post impact; (c) as-heat treated, post tension at room temperature; (d) as-heat treated, post tension at $650^{\circ} \mathrm{C}$; (e) as-heat treated, fractured by creep at $650^{\circ} \mathrm{C} / 690 \mathrm{MPa}$; (f) $\gamma^{\prime \prime}$ dissolved by high temperature solution and water quenching, after creep at $550^{\circ} \mathrm{C} / 200 \mathrm{MPa}$ for $120 \mathrm{~h}$.

The as-rolled microstructure is shown in Fig.5a, dislocation arrays and sometimes tangles could be easily observed. The post mechanical property test microstructures are shown in Fig.5b $-5 f$. The Fig5.b was taken from the place near the fracture surface of the impact sample with an 
as-heat treated microstructure, a high density of the dislocations were observed, and the dislocation arrays in different directions were usually intersected with each other, forming a network structure. This means that more dislocation sliding system could be operated under the high stress of impact. As shown in Fig.5c, dislocation arrays and tangles were easily to be observed at the place nearby the fracture surface of the alloy after tension at room temperature. As shown in Fig.5b, dislocations and sometimes twins were observed at the place nearby the fracture surface of the alloy after tension at $650^{\circ} \mathrm{C}$. As shown in Fig.5e, a large amount of thin twin bands was observed at the place nearby the fracture surface of the alloy crept at $650^{\circ} \mathrm{C}$ /690MPa, and dislocations were rarely observed. Comparatively, dislocations were observed apparently in the alloy crept at $550^{\circ} \mathrm{C} / 200 \mathrm{MPa}$ for $120 \mathrm{~h}$ when the $\gamma^{\prime \prime}$ phase was dissolved, and no twins were observed, as is shown in Fig.5f.

The relationship between the load type, stress, temperature and deformation mechanisms are summed up in Table 3 according to the results shown in Fig. 5

Table 3. Relationship between load type, temperature, and deformation mechanism of IN718 alloy.

\begin{tabular}{||l|l|l|l|l|}
\hline Deformation Form & $\begin{array}{l}\text { Stress for } \\
\text { Deformation }\end{array}$ & $\begin{array}{l}\text { Speed of } \\
\text { Deformation }\end{array}$ & Temperature & Mechanism \\
\hline \hline Rolling & Higher & Higher & Higher & Dislocation \\
\hline Impact at R.T. & Higher & Higher & Lower & Dislocation \\
\hline Tension at R.T. & Moderate & Moderate & Lower & Dislocation \\
\hline Tension at $650^{\circ} \mathrm{C}$ & Moderate & Moderate & Higher & $\begin{array}{l}\text { Dislocation, } \\
\text { Twinning }\end{array}$ \\
\hline Creep $($ heat treated) & Lower & Lower & Higher & $\begin{array}{l}\text { Twinning, } \\
\text { Dislocation? }\end{array}$ \\
\hline Creep $\left(\gamma^{\prime \prime}\right.$ free $)$ & Lower & Lower & Higher & Dislocation \\
\hline
\end{tabular}

\section{Discussion}

It is of great importance to determine the creep mechanism of the IN718 alloy for improving the creep property of the alloy. As shown in Fig.5e, twinning is an important deformation mechanism for the creep of the IN718 alloy, but it has not been studied thoroughly by now. The yield strength of the IN718 alloy is naturally high because the lattice mismatch between $\gamma^{\prime \prime}$ and $\gamma$ phase is inherently high. As a result, the dislocation can not slide until the stress exerted is high enough. In the test of impact and tension, the stress exerted was finally higher than the yield strength of the alloy, and dislocation was the main deformation mechanism of the IN718 alloy (see Fig5b-5d). The initial stress of this creep test was 690MPa, much lower than that of the yield strength of the IN718 alloy at $650^{\circ} \mathrm{C}$ (see Table 1), and the dislocation was difficult to begin the sliding. Under this condition, the partial dislocation, such as $1 / 6[112]$ might operate. It is well known that the sliding of the 1/6[112] dislocation would form a sacking fault or a twin of a single plane, and the piling of the stacking fault would form a twin of certain dimension. However, the exerted stress lower than the yield stress may be only a necessary factor for the above twining process, because the same IN718 alloy with a microstructure free from $\gamma^{\prime \prime}$ phase crept by dislocation sliding instead of twinning (see Fig.5f), and plenty of the superalloys strengthened by $\gamma^{\prime}$ phase also crept by dislocation sliding. So the twinning must be related with the precipitation of the $\gamma^{\prime \prime}$ phase.

As shown in Table 3, the IN718 alloy was deformed by dislocation sliding both at higher and lower temperature when a higher stress was exerted such as rolling or impact. With the 
decreasing of the deformation speed and the increasing of temperature (for example the impact, tension and creep), twining became an important deformation mechanism of the IN718 alloy. This implies that twinning is a thermal activated process governed by temperature and time.

The beneficial effect phosphorus on the creep properties is great as shown in Fig.2 and the numerous previous studies, and it was mainly owed to the improvement of the grain boundary cohesion by phosphorus segregation. It is no doubt that the higher phosphorus segregation at the grain boundary would influence the creep properties and especially the life because the alloy exhibited an intergranular failure mode during creep. However, the result shown in Table 2 verifies that phosphorus can also strengthen the grains or the $\gamma$ matrix of the IN718 alloy, and this effect may play a key role on decreasing the creep rate, because the grain deformation occupy the main part of the total creep deformation. Comparing the results shown in Fig.1 and Table 2, we may find some relationship between the effect of phosphorus on impact and tensile properties. When the phosphorus content was lower than $0.016 \%$, both of the two properties changed slightly. When the phosphorus content reached the level of $0.040 \%$, both of the two properties changed fiercely. The reduction of the impact energy means that the matrix became 'harder' and the plasticity declined, and the strength of the alloy increased. The simultaneous variation of the two properties with the phosphorus content verifies the truth of the two results shown in Fig. 1 and Table 2.

One may wonder why phosphorus did not influence the tensile properties of the IN718 alloy with an as-heat treated microstructure. As shown in Fig.4, the $\gamma^{\prime \prime}$ particles precipitated heavily in the $\gamma$ matrix during aging. Apparently, the sliding of dislocations had to cut through or bypass the $\gamma^{\prime \prime}$ particles, and the strength of the alloy was mainly determined by the $\gamma^{\prime \prime}$ phase. Without the $\gamma^{\prime \prime}$ particle, the dislocations could slide easily and the strengthening effect of phosphorus was manifested. During creep, the piling of single layer twins 'swept' the grains again and again, and this process would surely be slowed down with the strengthening of $\gamma$ matrix by phosphorus, and the creep rate was decreased as a result. To clarify how phosphorus influences the creep properties of the IN718 alloy, more work should be done to clarify how twins pass through the $\gamma^{\prime \prime}$ phase.

The addition of phosphorus and boron was found to increase the temperature capability of the IN718 alloy, exceeding $650^{\circ} \mathrm{C}$ limit $[6,7]$. The $\gamma^{\prime \prime}$ phase was not stable over $650^{\circ} \mathrm{Cand}$ would turned into $\delta$ phase, and the strength of the alloy would be decreased. Under this condition, Phosphorus would supply an additional strengthening effect according to the results shown in table 2, and this improved the temperature capability of the alloy.

\section{Conclusions}

1. Phosphorus greatly increased the rupture life, remarkably decreased the creep rate, reduced the impact energy of the IN718 alloy with a as-heat treated microstructure. It showed no influence on the tensile properties either at room temperature and $650^{\circ} \mathrm{C}$.

2. Phosphorus increased the yield strength of the IN718 alloy with a microstructure free from $\gamma^{\prime \prime}$ phase, and it decreased the creep rate by strengthening the $\gamma$ matrix.

3. Twinning was an important creep mechanism of IN718 alloy, creep twinning was a thermal activated process.

\section{Acknowledgement}

This work was founded by National Natural Science Foundation of china under the contract of No. 50271072 and 50471083. 


\section{References}

1. E. A. Loria ed., Superalloys 718, 625, 706 and various derivaties, (Pennsylvania, PA: TMS-AIME, 1994) 463

2. $\quad$ E. A. Loria ed., Superalloys 718, 625, 706 and various derivaties, (Pennsylvania, PA: TMS-AIME, 1997) 531

3. W. R. Sun, S. R. Guo, D. Z. Lu, and Z. Q. Hu, "Effect of phosphorus on the microstructure and stress rupture properties in an Fe-Ni-Cr base superalloy," Metall. Mater. Trans, 28A(1997), 649-654

4. W. R. Sun, S. R. Guo, J. H. Lee, N. K. Park, Y. S. Yoo, S. J. Choe, and Z. Q. Hu, "Effect of phosphorus on the $\delta-\mathrm{Ni}_{3} \mathrm{Nb}$ phase precipitation and stress rupture properties in alloy 718," Mater. Sci. Eng., A247(1998), 173-179

5. $\quad$ R. D. Kissinger etal. ed., Superalloys 1996, (Pennsylvania, PA: TMS-AIME, 1996) 589.

6. Z. Q. Hu, H. W. Song, S. R. Guo, and W. R. Sun, "Role of P, S, and B on creep behavior of alloy 718, ” J. Mater. Sci. Technol., 17(2001), 399-340.

7. N. Li, S. R. Guo, D. Z. Lu, W. R. Sun, X. N. Meng, Z. Q. Hu, "Effect of trace phosphorus and boron on the stress rupture and creep properties of direct aging IN718 alloy," Acta Metallurgica Sinica, 39(2003), 1255-1258 (in Chinese)

8. $\quad$ S. Hanada etal. Ed., The Fourth Pacific Rim International Conference on Advanced Materials and Processing, (Hawaii, The Japan Institute of Metals, 2001, 2719. 